\title{
Uso de softwares para o gerenciamento de bibliotecas: um estudo de caso da migração do sistema Aleph para o sistema Pergamum na Universidade de Santa Cruz do Sul
}

Fabiano Couto

Bibliotecário de Referência da Universidade de Santa Cruz do Sul (Unisc).

E-mail: fabianos@unisc.br

\section{Resumo}

Apresenta um dos primeiros processos de migração ocorrido entre os principais softwares pagos disponíveis atualmente no mercado brasileiro. Estão descritas as etapas da conversão do sistema Aleph para o sistema Pergamum, bem como as principais dificuldades enfrentadas e as soluções encontradas. O processo de transferência ora apresentado mostra-se um case que poderá servir como base para futuras conversões.

Palavras-chave

Biblioteca universitária; Catálogo de Acesso Público em Linha (OPAC); Migração; Aleph; Pergamum.

\section{Use of software for libraries management:} a case study of the conversion between Aleph and Pergamum system at the University of Santa Cruz do Sul

\section{Abstract \\ Presents one of the first cases of conversion occurred between the main commercial software for library management available in the Brazilian market nowadays. The stages of the conversion from the Aleph system to Pergamum system are described, as well as the main difficulties faced as well as the adopted solutions. This conversion process constitutes a case that could be possibly used as a basis for future conversions.}

Keywords

University library; Library OPAC; Conversion; Aleph; Pergamum.

\section{INTRODUÇÃO}

Para atender à demanda informacional da comunidade acadêmica da Universidade de Santa Cruz do Sul (Unisc), a Biblioteca Central adquiriu em 1997 o software Aleph para gerenciamento do acervo. Na época, esta escolha representava a aquisição de um sistema diferenciado pela qualidade dos serviços executados, sua capacidade de adaptação às necessidades de processamento e circulação de materiais e pelo suporte prestado por uma das maiores empresas na área de automação de biblioteca, a Ex Libris.

Entretanto, nos últimos anos, surgiram diversos softwares para uso em unidades de informação, incentivando a livre concorrência e disponibilizando no mercado sistemas com qualidade e suporte cada vez mais eficientes. Junto às novas ofertas que surgiram no mercado, também surgiu uma disputa de mercado dos concorrentes de softwares na mesma proporção que vem ocorrendo a grande proliferação de bibliotecas e centros de documentação que estão informatizando o seu acervo.

Analisando a evolução dos softwares para gerenciamento de bibliotecas, a partir das quatro gerações de sistemas para bibliotecas descritas por Rowley (2002), pode-se dizer que:

- a primeira geração de sistemas de gerenciamento de bibliotecas desenvolveu-se módulo a módulo. Com isso, a integração entre os módulos era muito limitada, sendo dada prioridade ao desenvolvimento do controle de circulação ou à catalogação;

- as estruturas de bases de dados diferiam entre si, podendo ser descritas como proprietárias. Isto dificultava qualquer generalização sobre a estrutura da base de dados. Já os sistemas de terceira e quarta geração são integrados e se baseiam em estruturas de base de dados relacionais e orientada a objetos;

- os sistemas de primeira geração haviam sido desenvolvidos para rodar em plataformas de equipamento específicas e utilizavam linguagens de programação e sistemas operacionais proprietários, além de serem 
projetados essencialmente para serem acessados pelo pessoal técnico;

- os sistemas de segunda geração rodavam em maior variedade de plataformas, mas foi só com o aparecimento dos sistemas baseados em UNIX e DOS que eles se tornaram muito mais portáveis. Os sistemas de quarta geração baseiam-se geralmente em UNIX ou Windows;

- a comunicação entre os sistemas foi uma característica dos sistemas de segunda geração, sendo possível, então, importar ou exportar dados entre sistemas de segunda geração;

- a partir dos sistemas de quarta geração, a importação e a exportação estão totalmente integradas, sendo possível acrescentar registros com um mero clique;

- os sistemas de quarta geração apresentam arquitetura cliente-servidor e módulos que facilitam o acesso a outros servidores na Internet (conectividade total na Internet);

- nos sistemas de terceira geração, há ampla disponibilidade de relatórios padronizados;

- a implementação de sistemas que empregavam todos os padrões apropriados ocorria de modo gradativo;

- o mesmo ocorria com o desenvolvimento mais proveitoso e direto da interação (interface) com o usuário. As cores são uma característica comum nos sistemas de terceira geração. Características de interface gráfica, tais como janelas, ícones, menus e manipulação direta, passaram a ser norma. Isso contrasta totalmente com as interfaces baseadas em comandos dos primeiros sistemas, em que os usuários precisavam envolver-se com o processamento em lotes e relatórios impressos;

- os sistemas de quarta geração permitem o acesso a múltiplas fontes a partir de uma interface multimídia. Isto simboliza a mudança na atenção dada aos usuários ou clientes ao longo das gerações dos diferentes sistemas;

- os catálogos em linha de acesso público (Opacs) da quarta geração de sistemas são acessados por meio de uma variedade de interfaces que só dependem da estação de trabalho cliente e do usuários. Essa variedade abrange tanto os terminais de acesso público com funções limitadas, quanto as complexas interfaces gráficas, que contam com poderosa gama de recursos de busca.

Alguns aspectos acerca da evolução dos sistemas para bibliotecas também são apontados por Côrte et alii (2002):
- a maioria dos sistemas de quarta de geração prevê a customização do mesmo e a expansão ou inclusão de novos módulos;

- nos anos 80, houve o desenvolvimento de aplicativos para o seu gerenciamento, garantindo ao bibliotecário maior agilidade no tratamento e recuperação da informação e domínio da tecnologia, tornando-se mais amigável, inclusive, para o usuário;

- a década de 90 caracteriza-se como o período em que mais surgiram empresas na área, e novas versões com atualizações e melhorias são disponibilizadas com determinada freqüência;

- os aspectos ergonômicos dos softwares passam a ser requisito importante na avaliação dos mesmos, pois estão diretamente relacionados à satisfação dos usuários com o seu manuseio;

- alguns softwares estão mais voltados a um tipo de biblioteca que outros. É o caso das bibliotecas universitárias e escolares. Por exemplo: alguns oferecem, dentro do módulo de Relatórios, a consulta da bibliografia (básica ou complementar) por disciplina. Esta consulta é exigida pelas Comissões de Especialistas do Ministério da Educação (MEC), quando da avaliação do acervo bibliográfico de determinado curso;

- catalogação possível em rede cooperativa;

- interesse em compatibilizar o sistema utilizado para o gerenciamento da biblioteca com os sistemas de controle de auto-atendimento;

- todos os softwares possuem capacidade e operam de maneira satisfatória, sem limitação do tamanho do acervo e do número de usuários acessando e/ou alimentando o banco de dados;

- a política de comercialização é a venda de licença de uso e o contrato de manutenção que garante a atualização do software com as novas versões.

Falar sobre o uso de softwares para o gerenciamento de bibliotecas não significa apenas falar do uso direto de computadores e acesso à base de dados, conforme Côrte et alii (2002, p. 25):

O cenário indica que se as bibliotecas e arquivos quiserem oferecer melhor serviço aos usuários e cumprir a sua missão, necessário se torna acompanhar passo a passo o desenvolvimento da sociedade, entender com melhor precisão os hábitos e os costumes dos usuários, 
adaptar as tecnologias às necessidades e quantidades de informação de que dispõem, e utilizar um sistema informatizado que privilegie todas as etapas do ciclo documental, em que a escolha recaia sobre uma ferramenta que contemple os recursos hoje disponíveis, sem se tornar obsoleta a médio e longo prazo.

A direção das bibliotecas da Unisc veio acompanhando as novas ofertas de softwares que surgiram no mercado nos últimos anos e, mediante a análise de um software que atendesse às suas necessidades de gerenciamento do acervo e que dispusesse de um suporte ágil, que fosse ao mesmo tempo economicamente interessante para a instituição, foi adquirido, em 2003, o software Pergamum, sendo possivelmente a primeira instituição a migrar do sistema Aleph para o Pergamum.

Nesse sentido, este artigo tem como objetivo descrever metodologicamente a migração do sistema Aleph para o sistema Pergamum, uma vez que contribui para o desenvolvimento e para o processo de ensinoaprendizagem da ciência da informação, oportunizando a integração entre profissões e profissionais da informação, já que destes são exigidas respostas produzidas pela evolução tecnológica.

Segundo Côrte et alii (2002), além do apoio institucional, dois tipos de profissionais são fundamentais a qualquer processo que envolva a informatização de bibliotecas: o profissional da área de documentação (bibliotecário) e o profissional de processamento de dados/informática (analista de sistemas), pois as tecnologias de informação facilitaram o processo, mas não eliminaram os conhecimentos específicos que cada um traz como resultado de sua formação acadêmica e profissional.

A ciência da informação tem sido sistematicamente atingida pela evolução das tecnologias de informação. Conseqüentemente, os profissionais desta área também, e a eles se tornam fundamentais a atualização e a educação continuada para a compreensão do paradigma atual.

O mercado está exigindo profissionais flexíveis, dinâmicos, ágeis e criativos, que consigam trabalhar em equipes multidisciplinares e estejam atentos ao processo de desenvolvimento tecnológico.

A seguir, está descrito o processo de migração entre o sistema Aleph para o sistema Pergamum, ocorrido na Biblioteca Central da Universidade de Santa Cruz do Sul.

Ci. Inf., Brasília, v. 34, n. 2, p. 105-111, maio/ago. 2005

\section{PROCESSO DE MIGRAÇÃO DO ALEPH PARA O PERGAMUM}

Excepcionalmente, qualquer processo de migração entre sistemas e a biblioteca deve ser o mais suave possível para todos os envolvidos - equipe responsável, staff da biblioteca e usuários. Para que isso ocorra, deve haver um planejamento com toda a equipe, ou seja, fornecedor do novo software e os responsáveis por essa tarefa dentro da biblioteca.

Portanto, vale lembrar que migrações de sucesso mantêm os dados (bibliográficos e administrativos), as funcionalidades e o fluxo de trabalho (a biblioteca não pode deixar de disponibilizar seus serviços durante a conversão) do sistema anterior, até que sejam incorporadas as características e capacidades do novo sistema ao servidor de produção que atende à biblioteca.

Conforme Côrte et alii (2002), para a aquisição ou troca de sistemas de automação de bibliotecas, torna-se necessária a organização em etapas a serem cumpridas, a qual demanda algum tempo e muita dedicação dos profissionais envolvidos, sendo, porém, altamente compensadora em termos de resultados obtidos.

As etapas decisórias do processo de migração descrito a seguir referem-se ao ocorrido na Biblioteca Central da Unisc, com os softwares Aleph e Pergamum.

\section{$1^{\underline{a}}$ etapa: Decisão}

Como justificativa pela troca de sistema nas bibliotecas Unisc, pode-se dizer que foi uma decisão institucional baseada em critérios tecnológicos e econômicos. Decisão esta que não abriu mão da qualidade dos serviços oferecidos pelo novo software ao nosso público-alvo. Iniciando pela Biblioteca Central, abandonou-se o Aleph e foi escolhido o Pergamum para gerenciar o acervo.

A literatura aponta que uma das recomendações para o sucesso na escolha de um software apropriado para cada biblioteca depende, em grande parte, da instituição. É fundamental compreender o conceito moderno de gestão da informação e fazer uma leitura real da instituição como um todo, para apresentar um sistema que atenda aos itens obrigatórios, imprescindíveis e desejáveis aos gestores.

\section{$2^{\underline{a}}$ etapa: Visitas e avaliações}

Após a decisão da aquisição de um novo sistema de gerenciamento de biblioteca compatível com as necessidades das bibliotecas Unisc, o nosso ponto de partida escolhido foi realizar um rodízio entre os 
funcionários (bibliotecários e auxiliares), a equipe da biblioteca responsável pela migração e funcionários do Setor de Informática da Instituição, para visitar bibliotecas de instituições de ensino superior com o intuito de avaliar os softwares utilizados por estas.

Dentre os principais aspectos dos sistemas avaliados pela equipe da Unisc designada para escolher o novo software, pode-se destacar:

- requisitos de hardware para servidor e cliente;

- requisitos de software para servidor e cliente (sistema operacional, banco de dados, entre outros);

- custos, taxa de manutenção, número de licença para uso do software;

- segurança, backup e integridade dos dados;

- upgrades de versões do sistema sem custo;

- qualidade dos serviços oferecidos pelo sistema: Quais os módulos que possui? É possível customizar suas funcionalidades conforme nossas necessidades?

- como funciona o suporte técnico? Há a possibilidade de compatibilidade do software com sistemas institucionais? Havendo a necessidade, é possível o desenvolvimento de futuras customizações para a Unisc? Aceitam sugestões, melhorias para o software?

As questões abaixo referem-se às funcionalidades e aos recursos dos módulos:

- é possível copiar registros bibliográficos? Existe uma rede de cooperação de catalogação padronizada?;

- código (numérico/alfanumérico) do registro bibliográfico e exemplar;

- formato dos relatórios e das estatísticas (principalmente para o MEC);

- controle de assinaturas e recebimento de fascículos;

- controle de autoridades;

- geração de etiqueta com código de barras, lombada etc.;

- possui serviço de disseminação da informação (DSI) ;

- formato dos registros bibliográficos está de acordo com o padrão ISO-2709;

- na web: quais as possibilidades de consultas, identificação de usuário, serviços on-line para usuários, como renovação e reserva.
A partir de avaliações como estas, foi possível comparálas com as nossas necessidades e com os nossos requisitos na condição de clientes. Assim, após reuniões internas, optamos pelo sistema Pergamum, por este ser compatível com as nossas exigências.

Então, visitamos o fornecedor do software para mais detalhes técnicos pertinentes à viabilidade da conversão entre Aleph e Pergamum. Confirmada esta possibilidade, iniciamos a terceira etapa.

\section{$3^{\mathbf{a}}$ etapa: $\mathrm{O}$ processo}

\section{Plano de Migração}

O planejamento da conversão, mapeando-se todos os pontos de alteração, com cronograma, deve ser desenvolvido juntamente com todos os envolvidos (staff da biblioteca, da informática e fornecedor do novo software), para torná-la o mais suave possível para o usuário e garantir o mínimo de suspensão dos serviços da biblioteca durante esta etapa. Exemplos de questões que a Biblioteca Central da Unisc considerou para o planejamento da etapa de migração:

- caso seja necessário atualizar hardware e software para o novo sistema, isto deve ser feito antecipadamente à conversão;

- devem ser reservados equipamentos (servidor e cliente) para realizar testes. Ou seja, a migração deve ser simulada e validada (pela biblioteca), mesmo que remotamente pelo fornecedor, para então ser aplicada;

- definir o cronograma juntamente com o fornecedor para disponibilizar a análise do sistema, a análise dos dados, as cópias dos arquivos necessários para realizar a simulação da migração (testes) e para realizar a conversão de fato, além de realizar os treinamentos de utilização do novo sistema com o staff da biblioteca;

- caso seja necessário reetiquetar o acervo, isto também deve ser realizado antecipadamente à conversão;

- se necessário, deve-se estabelecer novos fluxos de trabalho para que haja adequação do novo sistema à biblioteca e vice-versa.

\section{Análise do sistema}

A análise do sistema atual - que são as tabelas e campos, os relacionamentos entre tabelas (somente aqueles envolvidos no processo de migração) e sua política de funcionamento - deve ser documentada e mapeada para que o fornecedor do novo software possa fazer a ligação 
Uso de softwares para o gerenciamento de bibliotecas: um estudo de caso da migração do sistema Aleph para o sistema Pergamum na Universidade de Santa Cruz do Sul

com as tabelas e campos equivalentes no novo sistema. Ou seja, as necessidades da biblioteca já são especificadas em relação ao futuro sistema. Também é importante especificar informações adicionais, como códigos de subbibliotecas, códigos de tipos de obra, entre outros. Seguem exemplos (dados fictícios) da estrutura da documentação:

Formato de armazenamento dos registros bibliográficos em formato MARC:

\section{FIGURA 1}

\section{Formato MARC de um registro bibliográfico}

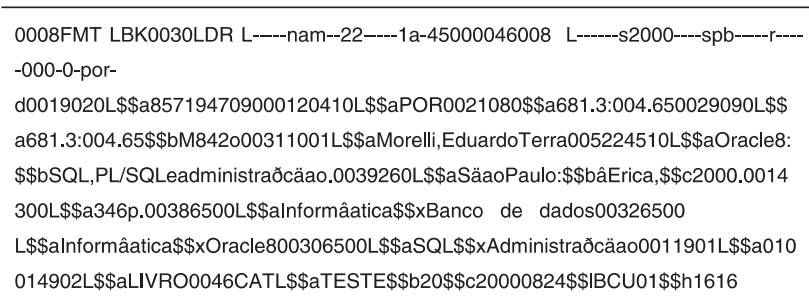

Para o trecho 005224510L\$ \$aOracle8:\$ \$bSQL,PL/ SQLeadministraðcäao da figura 1, explica-se:

0052 = comprimento do campo

$24510=$ campo e indicadores

$\mathrm{L}=$ latim

$\$ \$ \mathrm{a}, \$ \mathrm{~b}=$ subcampos

- Campos da tabela de exemplares:

A tabela 1 nos mostra o detalhamento de alguns campos da tabela de exemplares, utilizado como referência para o fornecedor do Pergamum.

\section{TABELA 1}

\section{Campos da tabela de exemplares}

\begin{tabular}{l|c|c|l}
\hline Nome campo & Nulo & Tipo & \multicolumn{1}{|c}{ Explicação do campo } \\
\hline codExemp & não & Int & $\begin{array}{l}\text { Código do exemplar. Este código faz } \\
\text { relacionamento com a tabela de } \\
\text { títulos (acervos) }\end{array}$ \\
\hline codSubBiblio & não & char(3) & $\begin{array}{l}\text { Código da sub-biblioteca do } \\
\text { exemplar }\end{array}$ \\
\hline codObraExemp & não & char(6) & $\begin{array}{l}\text { Código do tipo de obra do exemplar } \\
\text { (livro, DVD, periódico etc.) }\end{array}$ \\
\hline dtCriacao & não & Datetime & $\begin{array}{l}\text { Data de inclusão/criação do } \\
\text { exemplar no sistema }\end{array}$ \\
\hline dtAtualizacao & sim & Datetime & $\begin{array}{l}\text { Data de atualização (alteração) do } \\
\text { exemplar no sistema }\end{array}$ \\
\hline
\end{tabular}

Se houver alguma integração do novo sistema com sistemas institucionais, esta documentação também deve ser relatada. Por exemplo, no caso da Biblioteca Central, os usuários foram importados do sistema acadêmico para o Pergamum. Logo, também deve-se especificar ao fornecedor os procedimentos (base de dados, tabela, campos etc.) para esta tarefa.

\section{Análise dos dados}

Refere-se ao processo de coletar e repassar ao novo fornecedor as informações acerca dos registros bibliográficos e administrativos do software que a biblioteca esteja utilizando, quais sejam:

- formato do registro bibliográfico. Ex: USMARC, MARC21 etc.;

- campos. Ex: 100 - autor, 245 - título etc.;

- código de catalogação. Exemplo: AACR2, segundo nível, para todo tipo de documento;

- entrada de dados on-line;

- acentuação de caracteres (grupos de caracteres compatíveis entre os dois sistemas - exemplo: formato ASCII);

- formato ISO-2709 utilizado para registros internos e para importação e exportação dos registros bibliográficos;

- dados dos exemplares e demais registros administrativos (empréstimos, reservas, multas etc.);

- dados das assinaturas de periódicos, bem como o seu relacionamento com o registro bibliográfico e seus exemplares, ou seja, o kardex.

\section{Extração e exportação da base para testes e simulações}

Refere-se ao processo de disponibilizar para testes e simulações com o futuro sistema de biblioteca, uma cópia das bases bibliográfica (acervo da biblioteca) e administrativa (transações com o acervo). Estas cópias foram repassadas ao fornecedor do nosso novo software em arquivos, transferidos via FTP (File Transfer Protocol), juntamente com a documentação realizada nas etapas Análise do Sistema e Análise dos Dados.

Esse é o passo decisivo para a troca de sistema e para garantir a integridade do novo sistema. A biblioteca e o fornecedor do novo software devem estar comprometidos a trabalhar juntos para garantir e obter resultados satisfatórios, ou seja, nesta etapa define-se se há ou não a viabilidade de implantar um novo sistema na biblioteca 
que atenda às suas necessidades e interprete os dados que já existem cadastrados. No caso da Biblioteca Central da Unisc, felizmente os resultados esperados foram condizentes com o que esperávamos.

Também poderão ser conhecidos e mapeados ajustes na biblioteca e no novo sistema a serem implantados para a conversão de fato, bem como validar todo o processo de migração.

\section{Conversão e treinamento}

A partir dos resultados obtidos nos testes realizados, caso estes sejam satisfatórios, dá-se início aos procedimentos para a aplicação da conversão de fato. Além disso, todas as alterações propostas no Plano de Migração devem ter sido atendidas. Ou seja, a nova base convertida entra em produção.

Nesta fase, estavam presentes, na Biblioteca, um analista de sistemas do Pergamum, para trabalhar na conversão, e uma bibliotecária, responsável pelo treinamento. Este trabalho in loco por representantes do fornecedor gerou custos para a Biblioteca, que teve de arcar com as despesas de deslocamento e hospedagem de ambos. A conversão e o treinamento estavam incluídos no contrato de utilização e manutenção do software.

Conforme o Plano de Migração, o staff da biblioteca já deve ter recebido treinamento sobre a utilização do novo software e, portanto, estará interagindo com novas interfaces gráficas para realizar seu trabalho. Os usuários estarão interagindo com novas interfaces web para efetuar suas transações (como renovações e reservas) e realizar suas pesquisas.

A conversão do sistema ocorreu em duas etapas:

Primeira etapa: estendeu-se por uma semana e houve a conversão da base bibliográfica. Paralelamente aos ajustes finais à conversão dessa base, houve o treinamento do staff do Processamento Técnico. Enquanto analistas (fornecedor e equipe responsável pela migração) trabalhavam para organizar e finalizar os procedimentos que deveriam ser executados para migração de fato, uma bibliotecária era responsável por treinar essa parte do staff da biblioteca. Finalizado o treinamento, deu-se início à migração do Aleph para o Pergamum no período em que a Biblioteca estava fechada. Após esta conversão, houve um intervalo de duas semanas para adaptações e para o relato de dúvidas desse staff.

Segunda etapa: decorridas duas semanas, analista e bibliotecária do Pergamum retornaram à Biblioteca Central da Unisc para a conversão da base administrativa, estendendo-se por uma semana. Também foi possível sanar as dúvidas do staff do Processamento Técnico. Paralelamente aos ajustes finais para conversão dessa base (empréstimos, reservas, periódicos, dentre outros), houve o treinamento do staff da Referência, Aquisição, Periódicos, Coordenação e demais envolvidos. Finalizado o treinamento, deu-se início à migração do Aleph para o Pergamum no período em que a Biblioteca estava fechada.

\section{Pós-migração}

Para alguns tipos de obra, como os periódicos que possuíam código de barras alfanuméricos identificando seu exemplar, a tarefa de re-etiquetar para código de barras numéricos estendeu-se após a migração, devido ao prazo de que dispúnhamos para a conversão. O mesmo ocorreu após a migração dos sistemas nas bibliotecas dos outros campi. Com um plano de migração, elas também foram adaptadas e tiveram suas rotinas e equipamentos alterados para operarem com o Pergamum.

Atualmente, também existe, por parte da Biblioteca Central da Unisc, uma solicitação de customização de algumas funcionalidades do módulo de Aquisição para integração com outros sistemas institucionais.

De forma genérica, o sistema foi bem aceito por todo o staff, por toda a comunidade acadêmica e geral, atendendo às necessidades das bibliotecas e de seus usuários e disponibilizando novos serviços e recursos de informação via web.

\section{CONCLUSÃO}

Ao migrar do sistema Aleph para o Pergamum, a direção das bibliotecas da Unisc realizou uma experiência inovadora que trouxe forte impacto para o planejamento e estrutura do seu funcionamento, no que se refere à busca de agilidade na solução de problemas e no seu fluxo de trabalho.

Pode-se citar como principais dificuldades encontradas: nenhum histórico deste tipo de migração (nem com o fornecedor do Aleph, nem com o fornecedor do Pergamum), a extração correta da base para simulações na base do Pergamum e o treinamento ao usuário das novas telas de consulta do sistema Pergamum.

Para solucionar as duas primeiras dificuldades, realizaram-se inúmeras simulações e testes por parte do fornecedor Pergamum e pela biblioteca da Unisc. Foram extraídas várias versões da base do Aleph e importadas para a base do Pergamum, até a biblioteca validar os testes (conferir a integridade dos dados, verificar a acentuação, 


\section{Uso de softwares para o gerenciamento de bibliotecas: um estudo de caso da migração do sistema Aleph para o sistema}

Pergamum na Universidade de Santa Cruz do Sul

entre outros). Para auxiliar no treinamento dos usuários, atendentes da biblioteca revezaram-se periodicamente nos terminais de consulta. Também houve ampla divulgação impressa e ilustrativa das novas telas de consulta do sistema da biblioteca para a comunidade acadêmica.

Quanto à satisfação dos usuários que utilizam os serviços das Bibliotecas da Unisc, pode-se afirmar que, ao ter acesso ao novo sistema para realizar suas próprias pesquisas, reservar obras, renovar obras, consultar históricos de empréstimos, consultar débitos, incluir suas áreas de interesse, entre outros, com o uso da Internet, estes tiveram a oportunidade de agregar maior conhecimento dos recursos informacionais das bibliotecas e assim utilizá-los com mais efetividade e independência, além do aumento obtido nos aspectos que se referem a credibilidade, confiabilidade e precisão dos dados.

Relato de experiência recebido em 14/11/2005 e aceito para publicação em 05/01/2006.

\section{REFERENCIAS}

CÔRTE, Adelaide Ramos et al. Automação de bibliotecas e centros de documentação: o processo de avaliação e seleção de softwares. Ciência da Informação, Brasília: IBICT, v. 28, n. 3, p. 241-256, set./dez. 1999.

Avaliação de softwares para bibliotecas e arquivos: uma visão do cenário nacional. São Paulo: Polis, 2002.

- Automação de bibliotecas e centros de documentação: o processo de avaliação e seleção de softwares. Ciência da Informação, Brasília: IBICT, v. 28, n. 3, p. 241-256, set./dez. 1999.

DUMANS, M. L. F. Internet: novas perspectivas para a biblioteca no ciberespaço. Transinformação, Campinas, v. 5, n. 1/3, p. 72-79, jan./ dez. 1993.

FERREIRA, J. R. A biblioteca digital. Revista USP, São Paulo, n. 35, p. 46-57, set./nov. 1997.

FURRIE, Betty. Understanding MARC bibliographic: machine-readable cataloging. 5. ed. Washington, DC: Library of Congress, 2000. Disponível em: < http://lcweb.loc.gov/marc/umb/>. Acesso em: 25 jan. 2006

HESELTINE, Richard. Follett WP new directions in the library automation industry: prospects for higher education. [S.1.: s.n., 1995]. Disponível em: <http://www.niss.ac.uk/education/hefc/follett/wp/18.html >. Acesso em: 25 jan. 2006.

LAM, K.T. Planning for library automation. [S.l.: s.n., 2000]. Disponível em: <http://ihome.ust.hk/ lblkt/libauto/libauto.html>. Acesso em: 25 jan. 2006.

ROWLEY, Jennifer. A biblioteca eletrônica. Brasília: Briquet de Lemos/ Livros, 2002. Livros, 1994

Informática para bibliotecas. Brasília: Briquet de Lemos/

SHAW, W.; CULKIN, P. B. Systems that inform: emerging trends in library automation and network development. Annual Review of Science and Technology, v. 22, p. 265-284, 1987.

SILVA, Elenice Ávila da et al. Automação do Sistema de Bibliotecas da Universidade Federal do Rio Grande do Sul. In: SEMINÁRIO SOBRE AUTOMAÇÃO EM BIBLIOTECAS E CENTROS DE DOCUMENTAÇÃO, 5., 1994, São José dos Campos. Anais... São José dos Campos: UNIVAP, 1994. p.110-113.

SILVA, Marco (Org.). Educação on-line: teorias, práticas, legislação e formação. Loyola: São Paulo, 2003.

VICENTENI, L. A., MILECK, L. S. Desenvolvimento de sites na web em unidades de informação metodologias, padrões e ferramentas. Disponível em: < http://libdigi.unicamp.br/document/?code=3>. Acesso em: 25 jan. 2006. 